\title{
Sequential Fractionation by Organic Solvents Enhances the Antioxidant and Antibacterial Activity of Ethanolic Extracts of Fruits and Leaves of Terminalia bellerica from North Western Himalayas, India
}

\author{
Shikha Rangra Chandel', Vikas Kumar' ${ }^{1}$ Shikha Guleria ${ }^{1}$, Nitin Sharma ${ }^{2}$, Anuradha Sourirajan ${ }^{1}$, \\ Prem Kumar Khosla' ${ }^{1}$, David J. Baumler ${ }^{3,4,5}$, Kamal Dev ${ }^{1,3^{*}}$
}

\section{Shikha Rangra Chandel ${ }^{1}$, Vikas Kumar', Shikha Guleria1, Nitin Sharma², Anuradha Sourirajan', Prem Kumar Khosla', David J. Baumler ${ }^{3,4,5}$, Kamal Dev ${ }^{1,3^{*}}$}

\section{'Faculty of Applied Sciences and Biotechnology, Shoolini University, Post Box No. 9, Head Post Office, Solan, Himachal Pradesh, INDIA. 2Department of Biotechnology, Chandigarh Group of Colleges, Landran, Mohali, Punjab, INDIA. ${ }^{3}$ Department of Food Science and Nutrition, University of Minnesota-Twin Cities, St. Paul, MN, USA. \\ ${ }^{4}$ Microbial and Plant Genome Institute, University of Minnesota-Twin Cities, St. Paul, MN, USA. \\ ${ }^{4}$ Biotechnology Institute, University of Minnesota-Twin Cities, St. Paul, MN, USA \\ Correspondence \\ Dr. Kamal Dev}

Faculty of Applied Sciences and Biotechnology, Shoolini University, Post Box No. 9, Head Post Office,Solan, Himachal Pradesh, INDIA.

Phone no : +91-9418653905

E-mail: kamaldevbhardwaj1969@gmail. com

History

- Submission Date: 21-07-2018;

- Review completed: 26-10-2018

- Accepted Date: 20-11-2018

DOI : 10.5530/pj.2019.1.17

Article Available online

http://www.phcogj.com/v11/i1

Copyright

(c) 2019 Phcog.Net. This is an openaccess article distributed under the terms of the Creative Commons Attribution 4.0 International license.

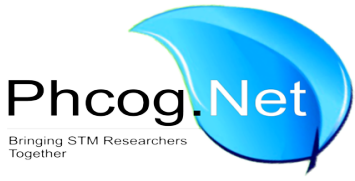

\begin{abstract}
Background: Terminalia bellerica belonging to family combretaceae is one of the major components of "Triphala", an Ayurvedic formulation. Objective: To evaluate antioxidant potential in the ethanolic extract and its active fraction (chloroform, ethyl acetate, $\mathrm{n}$ - butanol and aqueous fraction) from fruits and leaves of Terminalia bellerica. Materials and Methods: Folin-Ciocalteau method and aluminium chloride method was used to quantify total phenolic and flavonoid content respectively in ethanolic extract and their fractions from fruits and leaves of T. bellerica. The antioxidant activity was evaluated using total antioxidant activity, DPPH, FRAP and total antioxidant activity methods. Results: Total phenolics $(254.72 \pm 3.03 \mathrm{mg} / \mathrm{g}$ GAE and $227.52 \pm 1.38 \mathrm{mg} / \mathrm{g} \mathrm{GAE}$ ) and flavonoids (64.77 $\pm 1.24 \mathrm{mg} / \mathrm{gm} \mathrm{RE}$ and $75.57 \pm 1.38 \mathrm{mg} / \mathrm{gm} \mathrm{RE}$ ) content was higher in ethyl acetate fraction of both fruits and leaves sample of $T$. bellerica, respectively. The order of free radical scavenging activities was ethyl acetate fraction $>$ crude ethanolic extract $>$ n-butanol fraction $>$ chloroform fraction $>$ aqueous fraction. Similarly, ethyl acetate fraction of both fruits and leaves exhibited more antimicrobial activity as compared to that of ethanolic extract as revealed from agar well diffusion method with diameter of zone of inhibi-tion of $14.0 \pm 1.41 \mathrm{~mm}, 21.0 \pm 1.41 \mathrm{~mm}, 14.0 \pm 1.41 \mathrm{~mm}, 14.5 \pm 0.71 \mathrm{~mm}$ in fruits and $18.0 \pm 1.41 \mathrm{~mm}, 22.5 \pm 2.12 \mathrm{~mm}, 15.5 \pm 2.12 \mathrm{~mm}, 14.5 \pm 3.53 \mathrm{~mm}$ in leaves against $B$. subtilis, $S$. aureus, E. coli, K. pneumoniae, respectively. MIC values for fruits were $3.125 \mathrm{mg} / \mathrm{ml}, 0.375$ $\mathrm{mg} / \mathrm{ml}, 3.125 \mathrm{mg} / \mathrm{ml}, 3.125 \mathrm{mg} / \mathrm{ml}$ and for leaves were $1.5625 \mathrm{mg} / \mathrm{ml}, 0.19 \mathrm{mg} / \mathrm{ml}, 0.78 \mathrm{mg} /$ $\mathrm{ml}, 0.78 \mathrm{mg} / \mathrm{ml}$ against B. subtilis, S. aureus, E. coli, K. pneumoniae, respectively. Conclusion: The present study provides the evidence for comparative antioxidant and antibacterial potential of ethanolic extracts of fruits and leaves of T. bellerica. . Moreover, leaves can be promoted to be used for therapeutics and natural antioxidants.
\end{abstract}

Key words: Terminalia bellerica, Ethanolic extract, Fruits, Leaves, Antioxidant, Antimicrobial.

\section{INTRODUCTION}

The Indian Himalayan Region (IHR) comprises of a wide spectrum of biodiversity in diverse groups of flora, fauna and microorganisms. The Indian Himalayan Region showed the presence of rich biodiversity because of diverse habitat types influenced by wide altitudinal range (300-8000 $\mathrm{m}$ ), varied rainfall and precipitation, temperature regime and complex topographical features. ${ }^{1-2}$ This biodiversity is being utilized by the inhabitants of the IHR for various purposes such as medicine, food, fuel, fodder, timber, making agricultural tools, fiber, religious and various other purposes. ${ }^{2}$ Plants with medicinal properties enjoyed the highest reputation in the indigenous systems of medicine all over the world and still constitute one of the major sources of drugs in modern as well as tradi- tional systems of medicine in spite of tremendous development in the field of synthetic drugs and antibiotics. $^{3}$ In the remote areas of IHR where primary health centers are not available, inhabitants mostly rely on plants for the treatments of various ailments/ diseases, that is, cancer, kidney disorders, asthma, skin diseases, piles, etc. ${ }^{4}$

Phenolic compounds are secondary plant metabolites, present in plants act as powerful antioxidants which can protect the cellular mechanism from free radicals by acting as hydrogen donors and radical scavenger. ${ }^{5}$ Secondary metabolites are play important role for the normal growth, development and defense mechanisms of plants. ${ }^{6}$ Many studies have reported that phenolic compounds, such as fla-

Cite this article: Chandel SR, Kumar V, Guleria S, Sharma N, Sourirajan A, Khosla PK, Baumler DJ, Dev K. Sequential Fractionation by Organic Solvents Enhances the Antioxidant and Antibacterial Activity of Ethanolic Extracts of Fruits and Leaves of Terminalia bellerica from North Western Himalayas, India. Pharmacog J. 2019;11(1):94-101. 
vonoids and phenolic acids present in plants are accountable for their antioxidant potential..$^{7-8}$ Therefore, it is necessary to find out medicinal plants to validate their use and to reveal the active principle by isolation and characterization of their active constituents. Bioactive compound of natural products play major role in drug discovery. Nowadays, natural antioxidant has been promoted over synthetic antioxidant due to safety concerns. Natural antioxidant such as flavonoids, polyphenols and phenolics possess antioxidant properties due to their chelating and reducing capability. Antioxidants play important role to protect the body from damage caused by free radicals. Therefore, there is an increasing interest among researchers to identifying natural source of antioxidant. Conventionally practiced, natural antioxidants are already exploited commercially, but still there is demand to find more medicinal plants concerning the antioxidant potential.

T. bellerica is one of the major components of "Triphala", an Ayurvedic formulation which play important role to encourage health, immunity and long life. ${ }^{9}$ This antioxidant rich preparation is used in Ayurvedic medicine for the treatment of numerous diseases like anaemia, asthma, constipation, fever, jaundice and chronic ulcers. ${ }^{10}$ The fruits of T. bellerica have been phytochemically reported to contain beta-sitosterol, ellagic acid, galloyl glucose, mannitol, glucose, gallic acid, ethyl gallate, chebulagic acid, galactose, fructose, Rhamnose, ${ }^{11}$ Arjungenin, belleric acid, bellericoside, ${ }^{12-13}$ cannogenol and three lignans and one flavan. ${ }^{14}$ Therefore, the current study was focused on the comparative antioxidant and antibacterial activity of ethanolic extracts and active fractions of fruits and leaves of Terminalia bellerica and to promote the utilization of leaves in therapeutics.

\section{MATERIAL AND METHODS}

\section{Processing of fruit and leaves of $T$. bellerica}

The fruit and leaves of $T$. bellerica were collected from the Kangra region of Himachal Pradesh $\left(30^{\circ} 22^{\prime} 40^{\prime \prime}-33^{\circ} 12^{\prime} 40^{\prime \prime} \mathrm{N}\right.$ to $\left.75^{\circ} 45^{\prime} 55^{\prime \prime}-79^{\circ} 04^{\prime} 20^{\prime \prime} \mathrm{E}\right)$, India during the month of October, 2017. The collected fruits and leaves were thoroughly washed with running tap and then dried in hot air oven at $35-40^{\circ} \mathrm{C}$ and ground to fine powder.

\section{Cold maceration for extract preparation}

The dried powder of fruits and leaves $(10 \mathrm{~g})$ of $T$. bellerica were defatted and then ethanolic extract was prepared using a cold maceration method on a rotary shaker at $120 \mathrm{rpm}$ for 5 days to ensure complete extraction. ${ }^{15}$ Both the ethanolic extracts were then dissolved in autoclaved distilled water and successively fractionated with solvents such as chloroform, ethyl acetate and $n$-butanol. ${ }^{15-16}$

\section{Screening of phytocompounds in fruits and leaves extracts and its solvent fractions}

The ethanolic extract and its active fractions (chloroform fraction, ethyl acetate fraction, n-butanol fraction and aqueous fractions) of fruit and leaves of T. bellerica were screened for various phytocomponents such as phenolics, tannins, flavonoids, phytosteroids and saponins as per standard methods. ${ }^{17-18}$

\section{Quantitative analysis of total phenolic content (TPC) and total flavonoid content (TFC)}

Total phenolic content (TPC) and total flavonoid content (TFC) of the ethanolic extract and fractions of fruit and leaves of T. bellerica were quantified by using Folin-Ciocalteu method ${ }^{19}$ and aluminum chloride method. ${ }^{20}$ Total phenolic content was calculated from calibration curve of gallic acid (25-100 $\mu \mathrm{g})$ and expressed in terms of gallic acid equivalents (GAE) per gram of dry extract, whereas, TFC was quantified from the standard curve of rutin $(25-100 \mu \mathrm{g} / \mathrm{ml})$ and expressed as rutin equivalents (RE) per gram of dry extract.

\section{In-vitro antioxidant activity of different solvent fractions of fruits and} leaves of T. bellerica

Ethanolic extract and its active fractions such as chloroform, ethyl acetate, n-butanol and aqueous fraction were dissolved at a concentration of $1 \mathrm{mg} / \mathrm{ml}$ in ethanol. Then different dilutions were prepared $(2.5-10 \mu \mathrm{g} / \mathrm{ml})$ using ethanol. Ascorbic acid was used as a standard antioxidant compound.

\section{DPPH radical scavenging activity}

The ethanolic crude extract and active fraction were determined DPPH radical scavenging activity described by Barros et al. ${ }^{21}$ The percentage of inhibitory activity was calculated using the following equation-

$$
\% \text { Inhibition }=\left(A_{c}-A_{s} / A_{c}\right) \times 100
$$

where $A_{c}$ is the absorbance of the control. $A_{s}$ is the absorbance of the extract/standard.

\section{Ferric reducing antioxidant power (FRAP) assay}

The reducing power of crude extract and its active fraction was measured using the method described by Benzie and Strain..$^{22}$ The antioxidant capacity based on the ability to reduce ferric ions of extracts and its fractions were calculated from the linear calibration curve of $\mathrm{FeSO}_{4}$ (2.5-20 $\mu \mathrm{M})$ and expressed as $\mu \mathrm{M}$ Fe (II) equivalents per gram of extract.

\section{Total antioxidant activity assay}

The total antioxidant activity of the extracts was measured by the phosphomolybdenum method described by Prieto et al. ${ }^{23}$ Ascorbic acid was used as reference standard. The antioxidant activity is expressed as the number of equivalents of ascorbic acid (AAE).

\section{Antibacterial activity of ethanolic extracts of fruits and leaves and its solvent fractions}

Antibacterial activity was analysed against both Gram's positive (Staphylococcus aureus and Bacillus subtilis) and Gram's negative (Escherichia coli and Klebsiella pneumoniae), whereas, antifungal potential of extract was done against Saccharomyces cerevisiae (H1086), Candida albicans (ATCC90028) and Candida albicans (MTCC277). All the bacterial and fungal strains were revived from Yeast Biology Lab, Shoolini University, Solan, Himachal Pradesh, India.

Antibacterial activity of ethanolic extract of fruits and leaves and its solvent fractions was done using agar well diffusion method. ${ }^{24}$ In this method, nutrient agar (NA) plates were prepared and uniformly spreaded with the bacterial culture of $0.5 \mathrm{McF}$ arland Standard using sterile cotton swabs. The wells were punched with the cork borer $(6 \mathrm{~mm})$ in the agar and $50 \mu \mathrm{l}$ of ethanolic extract and their fractions extract of T. bellerica $(25 \mathrm{mg} / \mathrm{ml})$ were loaded in the wells. After the incubation of $18 \mathrm{~h}$ at $37^{\circ} \mathrm{C}$, the zone of inhibition was measured using HiAntibiotic Zone scale-C (Himedia Biosciences, Mumbai (India). Amoxyclav $(10 \mu \mathrm{g})$ was used as a positive control and DMSO (solvent) was used as negative control in the antibacterial assay. The tests were performed in triplicate and results were recorded as mean \pm S.D.

The minimum inhibitory concentration (MIC) of the extract was evaluated by broth dilution method described under CLSI. ${ }^{25}$ guidelines using 2, 3, 5-tripheny tetrazolium chloride. The methanolic extract were dissolved in DMSO and geometric dilutions ranging from $12.5-0.025 \mathrm{mg} / \mathrm{ml}$ of extract were prepared in a 96-welled micro titer plate, including one growth control (nutrient broth containing DMSO) and a positive control (NB broth inoculated with bacterial culture and containing Amoxyclav). Plates were incubated under normal atmospheric conditions at $37^{\circ} \mathrm{C}$ for $24 \mathrm{~h}$ for bacteria. After incubation, dye was added to each well and incubated for $2 \mathrm{~h}$. The color change was then observed visually. The growth was indicated by changes in color from purple to pink or colorless. The 
lowest concentration at which color change appeared was taken as the MIC value.

\section{Statistical analysis}

Total phenolic content, flavonoid content and half of minimum inhibitory concentration $\left(\mathrm{IC}_{50}\right)$ was determined by linear regression analysis method. Each sample was analyzed individually in triplicates and the results are expressed as the mean value $(n=3) \pm$ standard deviation. The values of zones of inhibition were expressed as mean \pm S.D. $(n=2)$.

\section{RESULTS}

\section{Sequential fractionation of selected plant extracts}

The yield of extracts obtained from $2 \mathrm{~g}$ of ethanolic extract of fruits and leaves ranged from $3.3 \%$ to $12.8 \%$. Among fruit extracts of T. bellerica, maximum extractive yield was observed in n-butanol fraction $(19.5 \%)$ and in case of leaves extracts, maximum extractive yield was obtained in aqueous fraction (12.8\%) (Table 1).

\section{Qualitative analysis of phytoconstituents of fruits and leaves extracts}

Phytochemical analysis revealed that flavonoids and phenolics were present in crude extract and its active fractions, except aqueous fractions. Similarly, alkaloids and steroids were absent in the chloroform and aqueous fraction in both ethanolic extracts. However, proteins were present in crude extract and active fraction (ethyl acetate and n-butanol fraction), but amino acid were absent in both ethanolic extract and their fractions (Table 2).

\section{Quantitative analysis of phytoconstituents of fruits and leaves extracts}

Total phenolic content was higher in ethyl acetate fraction $(254.72 \pm 3.03$ $\mathrm{mg} / \mathrm{g}$ GAE and $227.52 \pm 1.38 \mathrm{mg} / \mathrm{g}$ GAE), followed by ethanolic crude extracts $(227.89 \pm 2.038 \mathrm{mg} / \mathrm{gm}$ GAE and $206.07 \pm 1.89 \mathrm{mg} / \mathrm{gm}$ GAE) of both fruits and leaves sample of T. bellerica, respectively. In case of

Table 1: \% age yield of different fractions of fruit extracts of $T$. bellerica.

\begin{tabular}{ccccc}
\hline Extracts & \multicolumn{4}{c}{ \% age yield of extract } \\
\cline { 2 - 5 } & $\begin{array}{c}\text { Chloroform } \\
\text { fraction }\end{array}$ & $\begin{array}{c}\text { Ethyl acetate } \\
\text { fraction }\end{array}$ & $\begin{array}{c}\text { n-Butanol } \\
\text { fraction }\end{array}$ & $\begin{array}{c}\text { Aqueous } \\
\text { fraction }\end{array}$ \\
\hline Fruits & 2.8 & 12.8 & 19.5 & 4.3 \\
Leaves & 4.3 & 7.1 & 3.3 & 12.8 \\
\hline
\end{tabular}

flavonoids, higher amount was found in ethyl acetate fraction of fruits $(64.77 \pm 1.24 \mathrm{mg} / \mathrm{gm} \mathrm{RE})$ and leaves $(75.57 \pm 1.38 \mathrm{mg} / \mathrm{gm} \mathrm{RE})$ as compared to other fractions (Figure 1).

\section{In vitro antioxidant activity of ethanolic extract of fruits and leaves of T. bellerica and its fractions}

The antioxidant potential was determined by various methods such as total antioxidant activity, DPPH radical scavenging assay and FRAP assay.

\section{DPPH radical scavenging assay}

DPPH radical scavenging activity of the ethanolic extracts and its fractions of T. bellerica of leaves and fruits extract shows a dose-response curve in comparison to ascorbic acid (Figure 2). DPPH scavenging activity was found to be highest in ethyl acetate fraction of both fruits and leaves extract with $\mathrm{IC}_{50}$ of $6.03 \mu \mathrm{g} / \mathrm{ml}$ and $6.44 \mu \mathrm{g} / \mathrm{ml}$, respectively as compared to that of ascorbic acid $(6.3 \mu \mathrm{g} / \mathrm{ml})$. Order of DPPH scavenging for fruits extract was Ethyl acetate $(6.03 \mu \mathrm{g} / \mathrm{ml}>$ crude ethanolic extract $(6.33 \mu \mathrm{g} / \mathrm{ml})$ $>$ n-butanol fraction $(7.57 \mu \mathrm{g} / \mathrm{ml}>$ chloroform fraction $(15.39 \mu \mathrm{g} / \mathrm{ml})$ $>$ aqueous fraction $(97.57 \mu \mathrm{g} / \mathrm{ml})$. In case of leaves extract, the order was ethyl acetate $(6.44 \mu \mathrm{g} / \mathrm{ml}>$ crude ethanolic extract $(7.16 \mu \mathrm{g} / \mathrm{ml})>\mathrm{n}$-butanol fraction $(7.58 \mu \mathrm{g} / \mathrm{ml}>$ chloroform fraction $(20.41 \mu \mathrm{g} / \mathrm{ml})>$ aqueous fraction $(41.18 \mu \mathrm{g} / \mathrm{ml})$ (Table 3).

\section{FRAP Assay}

In case of fruits, the order of FRAP activity was ethyl fraction [2.55 $\mu \mathrm{M}$ Fe (II) equivalents] $>$ crude ethanolic extract [2.86 $\mu \mathrm{M}$ Fe (II) equivalents] > n-butanol fraction [3.09 $\mu \mathrm{M}$ Fe (II) equivalents] >chloroform fraction $[5.06 \mu \mathrm{M}$ Fe (II) equivalents] >aqueous fraction $[6.17 \mu \mathrm{M} \mathrm{Fe}$ (II) equivalents]. However, in case of leaves of T. bellerica, ethyl acetate fraction was found more active as compare to crude extract and other fractions (Figure 3). In case of leaves extract, the order was ethyl acetate [3.13 $\mu \mathrm{M}$ Fe (II) equivalents] >crude ethanolic extract [3.32 $\mu \mathrm{M}$ Fe (II) equivalents] $>$ n-butanol fraction $[5.05 \mu \mathrm{M}$ Fe (II) equivalents] $>$ chloroform fraction [11.16 $\mu \mathrm{M}$ Fe (II) equivalents] >aqueous fraction [12.05 $\mu \mathrm{M}$ Fe (II) equivalents] (Table 3).

\section{Total antioxidant activity}

Total antioxidant activity of ethanolic extract and its derived fraction was calculated from standard curve of ascorbic acid $(y=0.0111 \mathrm{x}-0.0092$; $\mathrm{R}^{2}=0.9995$ ) (Figure 4 ). Order of total antioxidant activity for fruit extract

Table 2: Comparative phytochemical screening of crude ethanolic extract and its fractions of fruits and leaves of $T$. bellerica. $(+)$ indicated the presence of phytochemical, whereas (-) indicated the absence of phytochemical. F-Fruits; L-Leaves.

\begin{tabular}{|c|c|c|c|c|c|c|c|c|c|c|}
\hline \multirow[t]{3}{*}{ Phytoconstituents } & \multicolumn{2}{|c|}{ Crude extracts } & \multicolumn{8}{|c|}{ Solvent fractions } \\
\hline & \multirow[b]{2}{*}{$F$} & \multirow[b]{2}{*}{$\mathrm{L}$} & \multicolumn{2}{|c|}{ Chloroform fraction } & \multicolumn{2}{|c|}{ Ethyl acetate fraction } & \multicolumn{2}{|c|}{ n-Butanol fraction } & \multicolumn{2}{|c|}{ Aqueous fraction } \\
\hline & & & $\mathrm{F}$ & $\mathrm{L}$ & $\mathrm{F}$ & $\mathrm{L}$ & $F$ & $\mathrm{~L}$ & $\mathrm{~F}$ & $\mathrm{~L}$ \\
\hline Alkaloids & + & + & & & + & + & + & + & & \\
\hline Phenolics and Tannins & + & + & + & + & + & + & + & + & + & + \\
\hline Flavonoids & + & + & + & + & + & + & + & + & + & + \\
\hline Steroids & + & + & & & + & + & + & + & & \\
\hline Carbohydrates & + & + & + & + & + & + & + & + & + & + \\
\hline Glycosides & + & + & + & + & + & + & + & + & & \\
\hline Proteins & + & + & & & + & + & + & + & & \\
\hline \multicolumn{11}{|l|}{ Amino-acids } \\
\hline Saponins & + & + & - & - & + & + & + & + & - & - \\
\hline
\end{tabular}




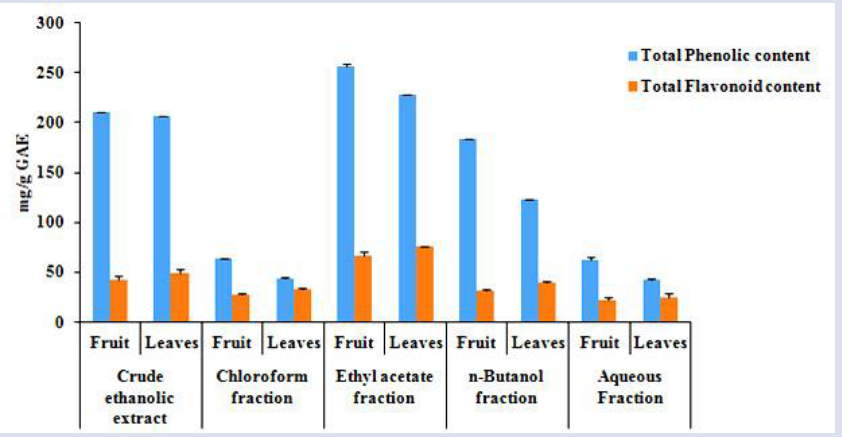

Figure 1: Quantification of total phenolics and flavonoids content in crude ethanolic extract of fruits and leaves and their fractions. Total Phenolic content was expressed as $\mathrm{mg} / \mathrm{gm}$ gallic acid equivalents (GAE), whereas flavonoid content was expressed in terms of $\mathrm{mg} / \mathrm{gm}$ rutin (RE).

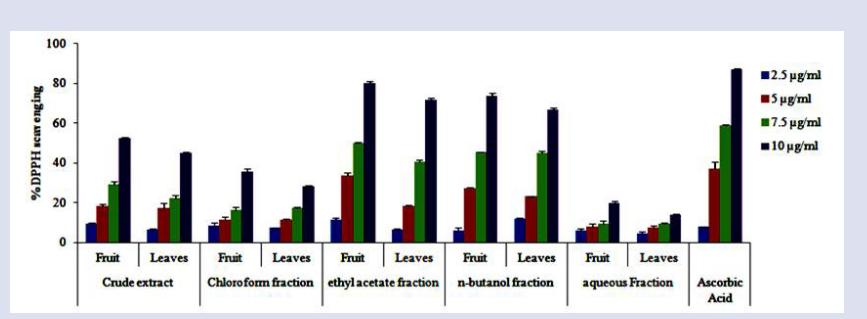

Figure 2: DPPH radical scavenging activity of ethanolic extract and its different fractions. \% DPPH activity was determined for fruits extract and leaves extracts and its fractions. The values represent mean \pm S.D. of three independent experiments.

Table 3: Half maximal inhibitory concentration $\left(\mathrm{IC}_{50}\right)$ of ethanolic extract and its active fractions from fruits and leaves of $T$. bellerica. F-Fruits; $\mathrm{L}$-leaves.

\begin{tabular}{|c|c|c|c|c|c|c|c|c|c|c|c|}
\hline \multirow{3}{*}{$\begin{array}{c}\text { Antioxidant } \\
\text { assay }\end{array}$} & \multicolumn{11}{|c|}{ Half maximal inhibitory concentration (IC50) } \\
\hline & \multirow{2}{*}{$\begin{array}{l}\text { Ascorbic } \\
\text { acid }\end{array}$} & \multicolumn{2}{|c|}{ Crude Extract } & \multicolumn{2}{|c|}{ Chloroform fraction } & \multicolumn{2}{|c|}{$\begin{array}{l}\text { Ethyl acetate } \\
\text { fraction }\end{array}$} & \multicolumn{2}{|c|}{ n-Butanol fraction } & \multicolumn{2}{|c|}{ Aqueous fraction } \\
\hline & & $\mathrm{F}$ & L & $\mathrm{F}$ & L & $\mathrm{F}$ & L & $\mathrm{F}$ & L & $\mathrm{F}$ & L \\
\hline $\mathrm{DPPH}(\mu \mathrm{g} / \mathrm{ml})$ & 639 & 633 & 7.16 & 15.39 & 20.41 & 6.03 & 6.44 & 7.57 & 7.58 & 97.57 & 41.18 \\
\hline $\operatorname{FRAP}(\mu \mathrm{M})$ & 1.58 & 2.86 & 3.32 & 5.06 & 11.16 & 2.55 & 3.13 & 309 & 5.05 & 6.17 & 12.05 \\
\hline $\begin{array}{l}\text { Total Antioxidant activity } \\
\qquad(\mu \mathrm{g} / \mathrm{ml})\end{array}$ & & 79.29 & 85.58 & 94.01 & 108.38 & 58.40 & 78.35 & 74.07 & 90.94 & 101.88 & 199.26 \\
\hline
\end{tabular}

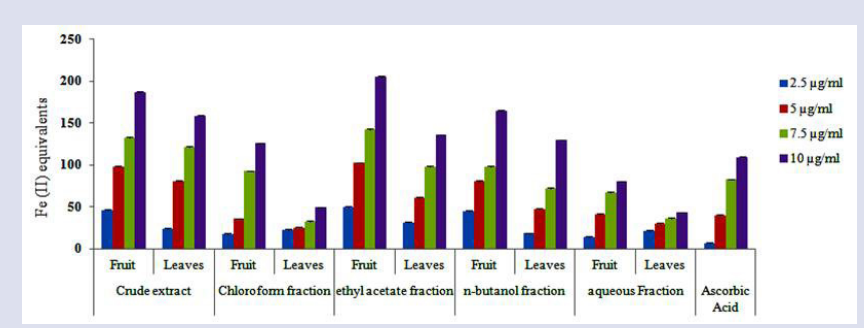

Figure 3: FRAP assay of ethanolic extract and its different fractions. FRAP assay was performed for fruits and leaves extracts of $T$. bellerica along with standard, ascorbic acid. The values represent mean \pm S.D. of three independent experiments.

was ethyl acetate fraction (58.40 AAE) $>$ n-butanol fraction (74.07 AAE) $>$ crude extract (79.29 AAE) >chloroform fraction (94.01 AAE) >aqueous fraction (101.88 AAE). In case of leaves extract, the order was ethyl acetate fraction (78.35 AAE) >crude extract (85.58 AAE) >n-butanol fraction (90.94 AAE) >chloroform fraction (108.38 AAE) >aqueous fraction (199.26 AAE) (Table 3).

\section{Antimicrobial activity of T. bellerica and its active fractions}

The ethanolic extracts and its derived fractions exhibited the good antibacterial activity against tested bacteria using disc diffusion method. The antimicrobial activity followed the pattern of variation of total phenolic and flavonoid content. The results from the agar well diffusion method, followed by measurement of minimum inhibitory concentration (MIC),

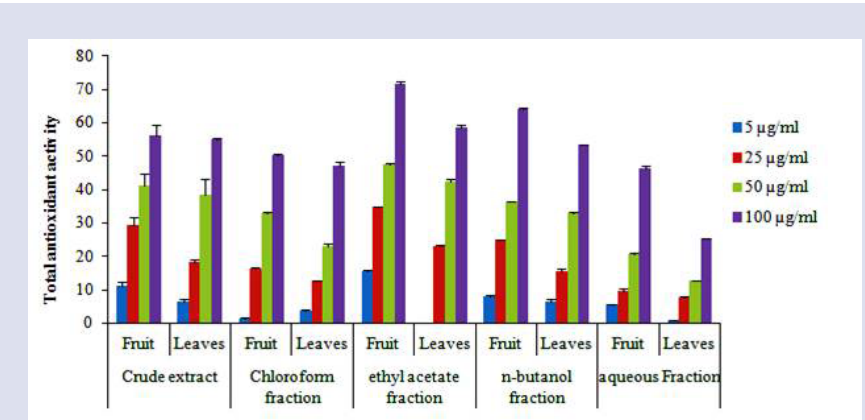

Figure 4: Total antioxidant assay of ethanolic extract and its different fractions. Total antioxidant assay was performed for fruits and leaves extracts of T. bellerica and expressed in terms of Ascorbic acid equivalents (AAE). The values represent mean \pm S.D. of three independent experiments.

indicated that ethyl acetate fraction of both fruits and leaves exhibited more antimicrobial activity as compared to that of ethanolic extract with diameter of zone of inhibition in $\mathrm{mm}$ were $14 \pm 1.41,21 \pm 1.41,14 \pm 1.41$, $14.5 \pm 0.71$ in fruits, whereas zone of inhibition diameters in $\mathrm{mm}$ were $18 \pm 1.41,22.5 \pm 2.12,15.5 \pm 2.12,14.5 \pm 3.53$ in leaves and MIC values for fruits were $3.125 \mathrm{mg} / \mathrm{ml}, 0.375 \mathrm{mg} / \mathrm{ml}, 3.125 \mathrm{mg} / \mathrm{ml}, 3.125 \mathrm{mg} / \mathrm{ml}$ and for leaves were $1.5625,0.19 \mathrm{mg} / \mathrm{ml}, 0.78 \mathrm{mg} / \mathrm{ml}, 0.78 \mathrm{mg} / \mathrm{ml}$ against 
Chandel, et al.: Medicinal Properties of Terminalia bellerica from North Western Himalayas

Table 4: Antibacterial activity of crude ethanolic extract and its fractions. Antibacterial activity of ethanolic extract and its fractions from fruits and leaves were evaluated against Gram's positive (B. subtilis, S. aureus) and Gram's negative (E. coli, K. pneumonia) bacterial strains. F-Fruits; L-leaves.

\begin{tabular}{|c|c|c|c|c|c|c|c|c|}
\hline \multirow{4}{*}{$\begin{array}{l}\text { Extract/ } \\
\text { fraction }\end{array}$} & \multicolumn{8}{|c|}{ Diameter of zone of inhibition (mm) } \\
\hline & \multicolumn{4}{|c|}{ Gram positive } & \multicolumn{4}{|c|}{ Gram negative } \\
\hline & \multicolumn{2}{|c|}{ B. subtilis } & \multicolumn{2}{|c|}{ S. aureus } & \multicolumn{2}{|c|}{ E.coli } & \multicolumn{2}{|c|}{ к. pneumoniae } \\
\hline & $\mathbf{F}$ & L & $\mathbf{F}$ & L & $\mathbf{F}$ & $\mathbf{L}$ & $\mathbf{F}$ & L \\
\hline Ethanolic extract & $13 \pm 1.41$ & $16 \pm 1.41$ & $19.5 \pm 0.71$ & $20 \pm 1.41$ & $13+1.41$ & $14.5 \pm 0.71$ & $14 \pm 1.41$ & $13 \pm 1.41$ \\
\hline Chloroform fraction & $11.5 \pm 0.71$ & $14 \pm 1.41$ & $14.5 \pm 0.71$ & $13.5 \pm 0.71$ & $10.5+0.71$ & $11 \pm 1.41$ & $10.5 \pm 0.71$ & $11 \pm 1.41$ \\
\hline Ethvl acetate fraction & $14 \pm 1.41$ & $18 \pm 1.41$ & $21 \pm 1.41$ & $22.5 \pm 2.12$ & $14 \pm 1.41$ & $15.5 \pm 2.12$ & $14.5+0.71$ & $14.5 \pm 3.53$ \\
\hline n-Butanol fraction & $13 \pm 1.41$ & $17 \pm 1.41$ & $19 \pm 1.41$ & $19 \pm 2.83$ & $13.5+0.71$ & $12.5 \pm 0.71$ & $13 \pm 1.41$ & $13 \pm 1.41$ \\
\hline Aqueous fraction & $10.5+0.71$ & $10.5 \pm 0.71$ & $12 \pm 1,41$ & $12.5 \pm 2.12$ & $10.5 \pm 0.71$ & $11 \pm 1.41$ & $10.5 \pm 0.71$ & $10.5 \pm 0.71$ \\
\hline Amoxvclav & $19.5+0.71$ & $19.5 \pm 0.71$ & $26 \pm 1.41$ & $26 \pm 1.41$ & $20 \pm 1.41$ & $20 \pm 1.41$ & $14.5 \pm 0.71$ & $14.5 \pm 0.71$ \\
\hline DMSO & $6.5 \pm 0$ & $6.5 \pm 0$ & $6.5 \pm 0$ & $6.5 \pm 0$ & $6.5 \pm 0$ & $6.5 \pm 0$ & $6.5 \pm 0$ & $6.5 \pm 0$ \\
\hline \multicolumn{9}{|c|}{ MIC (mg ml) } \\
\hline Ethanolic Extract & 6.25 & 3.125 & 1.562 & 0.375 & 6.25 & 1.5625 & 6.25 & 3.125 \\
\hline Chloroform fraction & 12.5 & 12.5 & 6.25 & 3.125 & 12.5 & 3.125 & 12.5 & 12.5 \\
\hline Ethvl acetate fraction & 3.125 & 1.5625 & 0.375 & 0.19 & 3.125 & 0.78 & 3.125 & 0.78 \\
\hline n-Butanol fraction & 6.25 & 3.125 & 1.56 & 0.75 & 3.125 & 1.5625 & 3.125 & 1.5625 \\
\hline Aqueous fraction & 12.5 & 6.25 & 12.5 & 6.25 & 12.5 & 3.125 & 12.5 & 12.5 \\
\hline Amoxvclav & 0.37 & 0.37 & 0.078 & 0.078 & 0.039 & 0.039 & 0.078 & 0.078 \\
\hline
\end{tabular}

B. subtilis, S. aureus, E. coli, K. pneumoniae, respectively. The leaves of T. bellerica showed more antibacterial potential in comparison to that of fruits extracts, clearly showing the importance of leaves in therapeutics (Table 4).

\section{DISCUSSION}

Medicinal plants have been used from ancient times for treatments for several diseases. The market use of medicinal plants is very high due to presence of many bioactive components, which cannot be synthesized artificially. ${ }^{26}$ Therefore recognition of antioxidant potential along with phytochemical variations for sustainable utilization of T. bellerica is the prime motive of the present study. Secondary metabolites such as phenolics and flavonoids are powerful antioxidant and have been used in many therapeutics such as diabetes, cardiovascular disorders, etc. ${ }^{27}$ Phenolic and flavonoids are the major secondary metabolites in the medicinal plants which are responsible for antioxidant activity. ${ }^{28}$ In present analysis, ethanolic crude extract and active fractions of fruits and leaves of T. bellerica revealed that flavonoids and phenolics were present in crude extract and its active fractions except aqueous fractions. However, proteins were present in crude extract and active fraction (ethyl acetate and n-butanol fraction), but amino acid were absent in both ethanolic extract and their fractions. There are various reports which supports the presence of alkaloids, flavonoids, phenolics, tannins, glycosides and saponins. ${ }^{29-31}$ Previously reported that phenolics, tannins, flavonoids, phytosteroids and saponins are also found in fruit and leaves of T. bellerica. ${ }^{32-35}$

Total phenolic $(254.72 \pm 3.03 \mathrm{mg} / \mathrm{gm}$ GAE and $227.52 \pm 1.38 \mathrm{mg} / \mathrm{gm} \mathrm{GAE})$ and flavonoids $(64.77 \pm 1.24 \mathrm{mg} / \mathrm{gm} \mathrm{RE}$ and $75.57 \pm 1.38 \mathrm{mg} / \mathrm{gm} \mathrm{RE})$ content was higher in ethyl acetate fraction of both fruits and leaves sample of $T$. bellerica, respectively. The present study showed that fruits extracts possessed maximum amount of TPC as compared to that of leaves. The results of study from Arya et al.33 also showed that methanolic fruits $(278.50 \pm 19.28 \mathrm{mg} / \mathrm{gm}$ GAE$)$ extracts showed higher amount of phenolic compound as compared leaves extract ( $259.28 \pm 6.42 \mathrm{mg} / \mathrm{gm} \mathrm{GAE})$. In the present study, higher amount of flavonoid content was found to be in the extracts of leaves, which was in accordance with the concept that higher phenolic content was not always accompanied with higher amount of flavonoids. ${ }^{36}$ The order of free radical scavenging activities was ethyl acetate fraction $>$ crude ethanolic extract $>$ n-butanol fraction $>$ chloroform fraction $>$ aqueous fraction with DPPH and FRAP assay for both fruits and leaves. However, the order was ethyl acetate fraction $>$ n-butanol fraction $>$ crude ethanolic extract $>$ chloroform fraction $>$ aqueous fraction in case of fruits and the order was ethyl acetate fraction $>$ crude ethanolic extract $>$ n-butanol fraction $>$ chloroform fraction $>$ aqueous fraction in leaves of T. bellerica with total antioxidant assay. Many studies have supported that higher antioxidant activity associated with total phenolic compounds. ${ }^{34-37}$ However, several studies showed that flavonoid act as natural antioxidants and showed capabilities to scavenge free radicals and active oxygen species. ${ }^{38-40}$

Evaluation of free radical scavenging activity and antioxidant potential of acetone extract of T. bellerica fruit was done by using in-vitro assays. ${ }^{41}$ Similarly, ethyl acetate fraction was found to be more effective as compared to crude acetone extracts in all antioxidant assays, i.e., DPPH, $\beta$-carotene bleaching inhibition and reducing power whereas for chelating ability on $\mathrm{Fe}^{+2}$ ion, crude acetone extract showed higher activity. It was concluded that polyphenolic rich fractions were more effective than the crude extract. ${ }^{41-42}$ Rastogi, investigated fruits, leaves and bark of T. bellerica for their antioxidant potential. It was observed that the leaves of T. bellerica, which are rich in phenolics and flavonoids, exhibit the highest antioxidant potential as evidenced by the better DPPH radical scavenging ability as well as the total antioxidant capacity. ${ }^{43}$

Similar to present study, ethanolic extract of Ficus pseudopalma into chloroform, ethyl acetate and aqueous fraction and found that ethyl acetate fraction rich in phenolic and flavonoids also showed more antibacterial activity. ${ }^{44}$ Similarly, studied the effect of T. bellerica and its fraction against $S$. typhi and S. typhimurium and it was found that alcoholic and aqueous extracts showed significant anti-microbial activity. ${ }^{45}$ Also, showed good antibacterial activity and antioxidant activity of crude methanolic extract of the fruits of T. bellerica Roxb along with its various organic fractions with moderate toxicity. ${ }^{46}$ Chanda et al. ${ }^{47}$ also investigated the antibacterial activity of T. bellerica stem and leaf 
acetone extracts and its fractions and found that both the extracts showed better activity towards Gram negative bacteria than Gram positive bacteria. This is very promising because it is reported that plant extracts show more activity towards Gram positive bacteria than Gram negative bacteria. ${ }^{47-49,38}$ This difference in activity is because of the difference in the cell wall structure of Gram positive and negative bacteria. Baliah and Astalakshmi ${ }^{50}$ studied the effect of solvents on the antibacterial activity of crude extract of $T$. chebula Retz. Using disc diffusion method against gram- negative bacteria such as E. coli, P. aeruginosa and K. pneumoniae and gram-positive bacteria such as $B$. subtilis, $S$. aureus. Of the eleven solvent used methanol, ethanol and acetone extracts showed more antibacterial activity than all other solvent extracts. ${ }^{50}$ Similar to present study, evaluation of antimicrobial activity of ethyl acetate, ethanol and aqueous extracts of the leaves from T. bellerica against selected Gram positive and Gram negative bacteria (E. coli, P. aeroginosa, S. aureus, B. subtilis). They found that $T$. bellerica extract shows significant inhibitory effect against Gram positive and Gram negative bacteria at high concentration. The study shows that ethanol and ethyl acetate leaf extracts of T. bellerica can be used as a potential source of antimicrobial agents. ${ }^{49}$ Enhancement of antibacterial activity in fruits and leaves extract may be attributed due to enrichment of phenolic and flavonoid content in ethyl acetate fraction as compared to all other fractions. similar to present study, study on ethanolic extract and its fraction of T. arjuna showed that the fraction enriched with phenolic and flavonoid content showed more antimicrobial and antioxidant activity as compared to crude ethanolic extract. ${ }^{51}$ The results suggested that antibacterial and antioxidant activity of plant extracts also depend on the type of solvent also.

\section{CONCLUSION}

Results obtained from the present study suggest that phenolic compounds are responsible for antioxidant potential of T. bellerica. Chloroform and aqueous fraction shows the neglible activity due to lesser amount of phytocompounds. However, ethyl acetate fraction shows more activity due to presence of phytocompounds. The fruits and leaves showed comparable phytochemistry as well as antioxidant potential. Therefore, the present studies validate the importance of leaves along with fruits of T. bellerica for therapeutics and food industry.

\section{ACKNOWLEDGEMENT}

The authors acknowledge Shoolini University, Solan, for providing infrastructure support to conduct the research work. Authors also acknowledge the support provided by Yeast Biology Laboratory, School of Biotechnology, Shoolini University, Solan, India.

\section{CONFLICT OF INTEREST}

The authors declare no conflict of interest.

\section{ABBREVIATIONS}

TPC: Total phenolic content; TFC: Total flavonoid content; DMSO: Dimethyl sulphoxide; NB: Nutrient broth; GAE: Gallic acid equivalents; RE: Rutin equivalents.

\section{REFERENCES}

1. Ray R, Gururaja KV, Ramchandra TV. Predictive distribution modeling for rare Himalayan medicinal plant Berberis aristata DC. J Env Bio. 2011;32(6):725.

2. Samant SS, Dhar U, Palni LM. Medicinal Plants of Indian Himalaya. Gyanodaya Prakashan. 1998.

3. Aswal BS. Biologically active medicinal plants of the Himalaya. Himalayan Medicinal Plants: Potential and Prospects. Nainital: Gyanodaya Prakashan. 2001;377-80.

4. Sharma PK, Lal B. Ethnobotanical notes on some medicinal and aromatic plants of Himachal Pradesh. Ind J Trad Knowledge. 2005;4:424-8.

5. Orhan DD, Ozcelik B, Hosbas S, Vural M. Assessment of antioxidant, antibacterial, antimycobacterial and antifungal activities of some plants used as folk remedies in Turkey against dermatophytes and yeast-like fungi. Turk $\mathrm{J}$ Bio. 2012;36(6):672-86.

6. Maisuthisakul P, Suttajit M, Pongsawatmanit R. Assessment of phenolic content and free radical-scavenging capacity of some Thai indigenous plants. Food Chem. 2007;100(4):1409-18

7. Katalinic $V$, Milos M, Kulisic T, Jukic M. Screening of 70 medicinal plant extracts for antioxidant capacity and total phenols. Food Chem. 2006;94(4):550-7.

8. Letelier ME, Molina-Berríos A, Cortés-Troncoso J, Jara-Sandoval J, Holst M, Palma K, et al. DPPH and oxygen free radicals as pro-oxidant of biomolecules. Toxicol in vitro. 2008;22(2):279-86.

9. Jagetia GC, Baliga MS, Malagi KJ, Kamath MS. The evaluation of the radioprotective effect of Triphala (an ayurvedic rejuvenating drug) in the mice exposed to $\gamma$-radiation. Phytomed. 2002;9(2):99-108.

10. Sandhya T, Lathika KM, Pandey BN, Mishra KP. Potential of traditional ayurvedic formulation, Triphala, as a novel anticancer drug. Cancer letters. 2006;231(2):206-14.

11. Row JR, Murty PS. Chemical examination of Terminalia bellerica Roxb. Ind J Chem. 1970;8:1047-8.

12. Nandy AK, Podder G, Sahu NP, Mahato SB. Triterpenoids and their glucosides from Terminalia bellerica. Phytochem. 1989;28(10):2769-72.

13. Yadav S. Antibiofilm formation activity of Terminalia bellerica plant extract against clinical isolates of Streptococcus mutans and Streptococcus sobrinus implication in oral hygiene. Int J Pharm Biol Sci Arch. 2012;3(4):816-21.

14. Valsaraj R, Pushpangadan P, Smitt UW, Adsersen A, Christensen SB, Sittie A, Nyman $U$, et al. New anti-HIV-1, antimalarial and antifungal compounds from Terminalia bellerica. J Nat Prod. 1997;60(7):739-42.

15. Mamedov N. Medicinal plants studies: history, challenges and prospective Med Aromat Plants. 2012;1(8):e133.

16. Ghosh G, Sahoo S, Das D, Dubey D, Padhy RN. Antibacterial and antioxidant activities of methanol extract and fractions of Clerodendrum viscosum Vent leaves. Indian J Nat Prod Res. 2014;5:132-42.

17. Harborne JB. Introduction to ecological biochemistry. Academic Press. 1988.

18. Khandelwal KR, Practical Pharmacognosy. (17th ed.). Nirali Prakashan, Pune. 2007.

19. Singleton VL, Orthofer R, Lamuela-Raventós RM. Analysis of total phenols and other oxidation substrates and antioxidants by means of Folin-ciocalteu reagent. Methods Enzymol. 1999;299:152-78.

20. Zhishen J, Mengcheng T, Jianming W. The determination of flavonoid contents in mulberry and their scavenging effects on superoxide radicals. Food Chem. 1999;64(4):555-9.

21. Barros L, Ferreira MJ, Queiros B, Ferreira IC, Baptista P. Total phenols, ascorbic acid, $\beta$-carotene and lycopene in Portuguese wild edible mushrooms and their antioxidant activities. Food Chem. 2007:103(2):413-9.

22. Benzie IF, Strain JJ. The ferric reducing ability of plasma (FRAP) as a measure of "antioxidant power": the FRAP assay. Anal Biochem. 1996;239(1):70-6.

23. Prieto P, Pineda M, Aguilar M. Spectrophotometric quantitation of antioxidant capacity through the formation of a phosphomolybdenum complex: specific application to the determination of vitamin E. Anal Biochem. 1999;269(2):337-41.

24. Perez C. Antibiotic assay by agar-well diffusion method. Acta Biol Med Exp. 1990;15:113-5.

25. CLSI. Methods for Dilution Antimicrobial Susceptibility Tests for Bacteria that Grow Aerobically, Approved Standard. $9^{\text {th }}$ ed. 950 West Valley Road, Suite 2500 Wayne, Pennsylvania 19087, USA: Clinical and Laboratory Standards Institute. 2012. CLSI document M07eA9.

26. Rice-Evans C, Miller N, Paganga G. Antioxidant properties of phenolic compounds. Trends Plant Sci. 1997;2(4):152-9.

27. Lin D, Xiao M, Zhao J, Li Z, Xing B, Li X, et al. An overview of plant phenolic compounds and their importance in human nutrition and management of type 2 diabetes. Molecules. 2016;21(10):1374

28. Cheynier V. Phenolic compounds: from plants to foods. Phytochem Reviews 2012;11(2-3):153-77.

29. Aqil F, Ahmad I, Mehmood Z. Antioxidant and free radical scavenging properties of twelve traditionally used Indian medicinal plants. Turk J Bio. 2006;30(3):177-83

30. Abraham A, Mathew L, Samuel S. Pharmacognostic studies of the fruits of Terminalia bellerica (Gaertn.) Roxb. J Pharmacog Phytochem. 2014;3(2):45-52.

31. Ram J, Moteriya P, Chanda S. Phytochemical screening and reported biological activities of some medicinal plants of Gujarat region. J Pharmacog Phytochem. 2015;4(2):192-8

32. Mety SS, Mathad P. Antioxidative and free radical scavenging activities of Terminalia species. Int Res J Biotech. 2011;2(5):119-27.

33. Arya A, Nyamathulla S, Noordin MI, Mohd MA. Antioxidant and hypoglycemic activities of leaf extracts of three popular Terminalia species. J Chem. 2012:9(2):883-92.

34. Rakholiya K, Vaghela P, RathodT, Chanda S. Comparative study of hydroalcoholic 
extracts of Momordica charantia L. against foodborne pathogens. Ind J Pharma Sci. 2014;76(2):148.

35. Chandel SR, Dev K, Khosla PK. Comparative Antioxidant Potential of Leaves and Fruit Extracts of Terminalia bellerica Roxb from Himachal Pradesh. Int J Pharma Sci Review Res. 2016;38:216-22.

36. Chaudhari GM, Mahajan RT. Comparative antioxidant activity of twenty traditional Indian medicinal plants and its correlation with total flavonoid and phenolic content. Int J Pharma Sci Review Res. 2015;30(1):105-11.

37. Petridis A, Therios I, Samouris G, Tananaki C. Salinity-induced changes in phenolic compounds in leaves and roots of four olive cultivars (Olea europaea L.) and their relationship to antioxidant activity. Env Exp Bot. 2012;79:37-43.

38. Chanda S, Dudhatra S, Kaneria M. Antioxidative and antibacterial effects of seeds and fruit rind of nutraceutical plants belonging to the Fabaceae family. Food Function. 2010;1(3):308-15.

39. Das PR, Islam MT, Mahmud AS, Kabir MH, Hasan ME, Khatun Z, et al. An ethnomedicinal survey conducted among the folk medicinal practitioners of three villages in Kurigram district, Bangladesh. Am Eurasian J Sustain Agri. 2012;6:85-96.

40. Arun KB, Chandran J, Dhanya R, Krishna P, Jayamurthy P, Nisha P. A comparative evaluation of antioxidant and antidiabetic potential of peel from young and matured potato. Food Biosci. 2015;9:36-46

41. Guleria S, Tiku AK, Rana S. Antioxidant activity of acetone extract/fractions of Terminalia bellerica Roxb Fruit. Ind J Biochem Biophysics 2010;47110-16.

42. Sannigrahi S, Mazuder UK, Pal DK, Parida S, Jain S. Antioxidant potential of crude extract and different fractions of Enhydra fluctuans Lour. Iranian J Pharma Res. 2010;9(1):75-82.

43. Rastogi S, Pandey MM, Rawat AK. Phytochemical analysis, phenolic content and antioxidant properties of different parts of Terminalia bellirica (Gaertn.) Roxb.-A comparative study. Ind J Trad Knowledge. 2018;17:370-5.

44. DeLas LMC, Santiago L, Ramos JD. Antibacterial activity of crude ethanolic extract and solvent fractions of Ficus pseudopalma Blanco leaves. Asian Pacific J Tropical Dis. 2014;4(5):367-71.

45. Madani A, Jain SK. Anti-Salmonella activity of Terminalia bellerica: in vitro and in vivo studies. Indian J Exp Bio. 2008;46:817-21.

46. Alam MB, Zahan R, Hasan M, Khan MM, Rahman MS, Chowdhury NS, et al. Thank You, a good research antioxidant, antimicrobial and toxicity studies of the different fractions of fruits of Terminalia belerica Roxb. Global J Pharmacol. 2011;5(1):07-17.

47. Chanda S, Menpara D, Desai D. Antimicrobial activity of Terminalia bellerica lea and stem collected from two different sites. Am J Phytomed Clinical Therapeutics. 2013;1(9):721-33.

48. Fernández-Agulló A, Pereira E, Freire MS, Valentao P, Andrade PB, GonzálezÁlvarez $\mathrm{J}$, et al. Influence of solvent on the antioxidant and antimicrobial properties of walnut (Juglans regia L.) green husk extracts. Ind Crops Prod. 2013:42:126-32

49. Agarwal P, Pal K, Pal A. Antimicrobial activity in Aegle mermalos and Terminalia bellirica in different extract. Int J Adv life Sci. 2017:10:31-5.

50. Baliah NT, Astalakshmi A. Phytochemical analysis and antibacterial activity of extracts from Terminalia chebula Retz. Int J Curr Microbiol Appl Sci. 2014;3(3):992-9.

51. Kumar V, Sharma N, Sourirajan A, Khosla PK, Dev K Comparative evaluation of antimicrobial and antioxidant potential of ethanolic extract and its fractions of bark and leaves of Terminalia arjuna from north-western Himalayas, India. J Trad Complement Med. 2018:8(1):100-6.

\section{GRAPHICAL ABSTRACT}

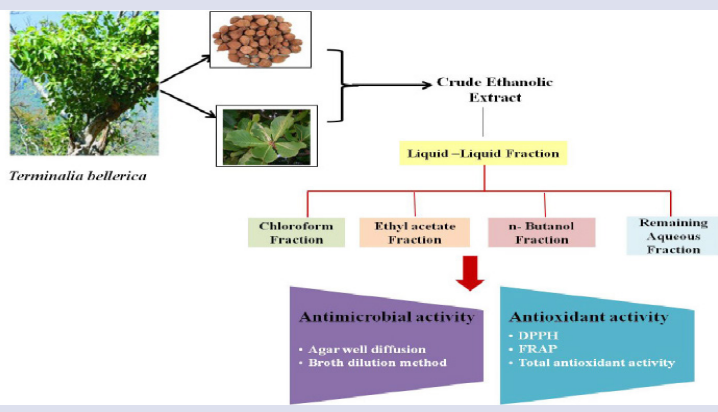

\section{SUMMARY}

- Terminalia bellerica is one of the most important medicinal plant. We compared antimicrobial activity and antioxidant activity in extracts of fruit and leaves of Terminalia bellerica. Extracts of fruit and leaves showed comparable antimicrobial and antioxidant activities. Therefore, extracts of both fruit and leaves of Terminalia bellerica could be used to develop functional food ingredients and immunodulators for health benefits. Since fruit and leaves showed antimicrobial activity, hence could be used as bio-based food preservatives.

\section{ABOUT AUTHORS}

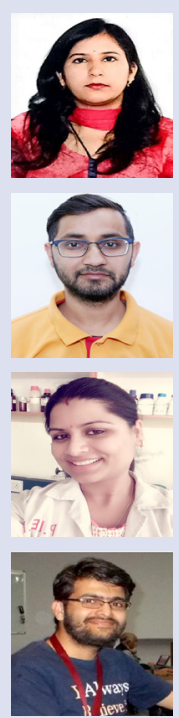

Shikha Rangra Chandel PhD research scholar at Shoolini University.

Dr Vikas Kumar is Assistant Professor, Faculty of Applied Sciences and Biotechnology at Shoolini University.

Shikha Guleria is $\mathrm{PhD}$ research scholar at Shoolini University.

Dr Nitin Sharma is Assistant Professor in the Department of Biotechnology, Chandigarh Group of Colleges, Landran, Mohali, Punjab, INDIA

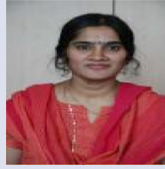

Dr Anuradha Sourirajan is Professor and Dean, Faculty of Applied Sciences and Biotechnology, Shoolini University. 


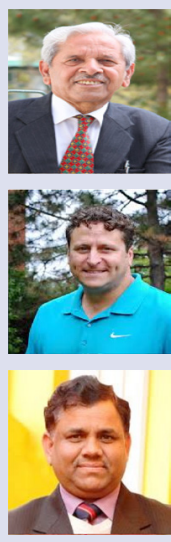

Prof. P.K. Khosla is Vice Chancellor of Shoolini University.

Dr David J Baumler is Assistant Professor of Molecular Food Safety Microbiology, Department of Food Science and Nutrition, BioTechnology Institute, Microbial and Plant Genome Institute, University of MinnesotaTwin Cities, St. Paul, MN, USA.

Dr Kamal Dev is Professor in the Faculty of Applied Sciences and Biotechnology at Shoolini University and Research Scientist at Department of Food Science and Nutrition, University of Minnesota-Twin Cities, St. Paul, MN, USA.

Cite this article: Chandel SR, Kumar V, Guleria S, Sharma N, Sourirajan A, Khosla PK, Baumler DJ, Dev K. Sequential Fractionation by Organic Solvents Enhances the Antioxidant and Antibacterial Activity of Ethanolic Extracts of Fruits and Leaves of Terminalia bellerica from North Western Himalayas, India. Pharmacog J. 2019;11(1):94-101. 